\title{
Sources and preservation of sedimentary organic matter in the Southern Bohai Sea and the Yellow Sea: Evidence from lipid biomarkers
}

\author{
Tian Lin ${ }^{\mathrm{a}, \mathrm{b}}$, Lifang Wang ${ }^{\mathrm{b}}$, Yingjun Chen ${ }^{\mathrm{a}, *}$, Chongguo Tian ${ }^{\mathrm{a}}$, Xiaohui Pan ${ }^{\mathrm{a}}$, Jianhui Tang ${ }^{\mathrm{a}}, \mathrm{Jun} \mathrm{Li}^{\mathrm{c}}$

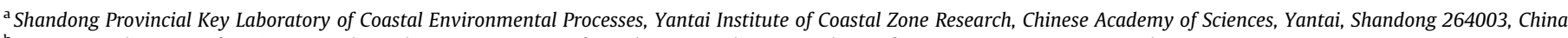 \\ ${ }^{\mathrm{b}}$ State Key Laboratory of Environmental Geochemistry, Institute of Geochemistry, Chinese Academy of Sciences, Guiyang 550002, China \\ 'State Key Laboratory of Organic Geochemistry, Guangzhou Institute of Geochemistry, Chinese Academy of Sciences, Guangzhou 510640, China
}

\section{A R T I C L E I N F O}

\section{Article history:}

Available online 15 August 2014

\section{Keywords:}

Lipid biomarker

Organic matter

Sources and preservation

Sediment

Southern Bohai Sea and Yellow Sea

\begin{abstract}
A B S T R A C T
The region of Southern Bohai Sea (SBS) and Yellow Sea (YS) represents one of the best examples of large river-dominated ocean margins. The transport and accumulation of sediments played a primary role in distribution of the lipids in the region and could lead to a preferential accumulation of these more refractory land-based lipids. The spatial distribution of total organic carbon (TOC) matched with the lipid distributions over the shelf, and high TOC presented in the central YS, but TOC burial fluxes decreased from $110 \mathrm{ton} / \mathrm{km}^{2} / \mathrm{yr}$ of SBS to $25-32$ ton $/ \mathrm{km}^{2} / \mathrm{yr}$ of YS. Good correlations were observed between terrestrial $n$-alkanes and TOC in the sediments of SBS and northern YS, but they were poor for southern YS, meanwhile higher ratios of $n \mathrm{C} 27+n \mathrm{C} 29+n \mathrm{C} 31 / n \mathrm{C} 15+n \mathrm{C} 17+n \mathrm{C} 19(12 \pm 6)$ were observed in SBS, and lower in YS $(2.2 \pm 1.0)$, suggesting the Yellow River discharge was an important source of terrestrial organic matter to the shelf.
\end{abstract}

(c) 2014 Elsevier Ltd. All rights reserved.

\section{Introduction}

Marginal seas play a significant role in the global carbon cycle because more than $80 \%$ of the global organic matter (OM) in oceans is buried in coastal marine systems adjacent to rivers (Goni et al., 2006), and it is generally considered that the major part of OM is produced by phytoplankton and so that only a small fraction is derived from terrestrial organic matter (TOM) (Hedges and Keil, 1995). However, large river-derived materials (water, sediments and TOM) entering seas have a tremendous effect on distribution and transport of OM in estuaries, coastal zones, and even continental shelf (Fernandes et al., 1999; Xing et al., 2011). Recent years, sedimentary $\mathrm{OM}$ in continental shelf has attracted more research subjects and common concerns, due to the origins, transport and decomposition are complex (Liu et al., 2012; Hu et al., 2013).

One of the best examples of the large river-dominated continental shelves is Southern Bohai Sea (SBS) and Yellow Sea (YS) (by the Yellow River). The Yellow River-derived sediments could reach $80-\mathrm{m}$ water depth in the center of YS, about $700 \mathrm{~km}$ from the river mouth (Yang and Liu, 2007). On hand, large amounts of TOM are annually transported from the continent to the ocean with the Yellow River-derived sediment transport. It was estimated that sediment discharge from the Yellow River to the sea

\footnotetext{
* Corresponding author. Tel./fax: +86 05352109159.

E-mail address: yjchen@yic.ac.cn (Y. Chen).
}

(approximately $1 \times 10^{9}$ ton/yr) was the second largest input from a single river worldwide, and the total organic carbon discharge accounted for $1 \%$ of total organic carbon transported by rivers into ocean worldwide in history (before 1990) (Zhang et al., 2013). On the other hand, due to the transport and deposition of riverderived fine-grained sediments are controlled by estuarine processes, tidal currents, shelf circulation and episodic storm, those fine-grained sediments accumulate in the central areas of open sea and form isolated mud patches (Alexander et al., 1991; Lim et al., 2007). In a recent study by Hu et al. (2011) was stated: the hydrodynamic transport and depositional mechanism of those river-derived fine-grained sediments might be the dominant factors in controlling the spatial distribution and fate of organic pollutants in YS.

SBS and YS, as a typical epicontinental shelf of the Western Pacific region, receive about $10 \%$ of the world's river sediment load and consequent large amount of OM (Lim et al., 2007). For a better understanding of the biogeochemical cycles of those OM in the region, it is essential to identify the sources of OM and to understand the key processes that responsible for the fate of OM. Lipids, the main structural component in living organisms, are well suited for such studies: to detect the sources and distribution of OM in marginal seas. For example, the presence of $n \mathrm{C} 27, n \mathrm{C} 29$, and $n C 31 n$-alkanes indicates that land-plant epicuticular waxes have been important sources of land lipids to sediment (Eglinton and Hamilton, 1967). Campesterol, sitosterol and stigmasterol occur 
in cell membranes, and they generally represent terrestrial higherplant input to OM pool in sediment (Gagosian et al., 1983). In this study, lipids (n-alkanes, $n$-alkanols and selected sterols) were extracted in the sediments from different marine areas (SBS, Northern Yellow Sea (NYS) and Southern Yellow Sea (SYS)). The present study was conducted to investigate the potential input sources and spatial divergence of $n$-alkanes, $n$-alkanols and selected sterols in SBS and YS, with the aims of examining the transport and preservation of OM, especially TOM.

\section{Materials and methods}

\subsection{Sample collection}

Twenty-three surface sediments $(0-3 \mathrm{~cm})$ on six sections (according to their latitude $34^{\circ} \mathrm{N}, 35^{\circ} \mathrm{N}, 36^{\circ} \mathrm{N}, 37^{\circ} \mathrm{N}, 38^{\circ} \mathrm{N}$ and $38.75^{\circ} \mathrm{N}$ ) covering most of YS (Fig. 1) were collected in September, 2009 using the R/V Science I of the Institute of Oceanology, Chinese Academy of Sciences. Eighteen surface sediments in SBS were collected in September, 2009. Surface sediment samples were collected using a stainless steel box corer. All sediment samples wrapped in aluminum foil were stored at $-20^{\circ} \mathrm{C}$ until analysis.

\subsection{Lipids analysis}

This method description is exactly the same text as in Xiong et al. (2010). Sediment samples for lipid determination were first Soxhlet extracted for $72 \mathrm{~h}$ with dichloromethane/methanol (9:1 $\mathrm{v} / \mathrm{v}$ ) to obtain the soluble fraction (free lipids). Sulfur was removed

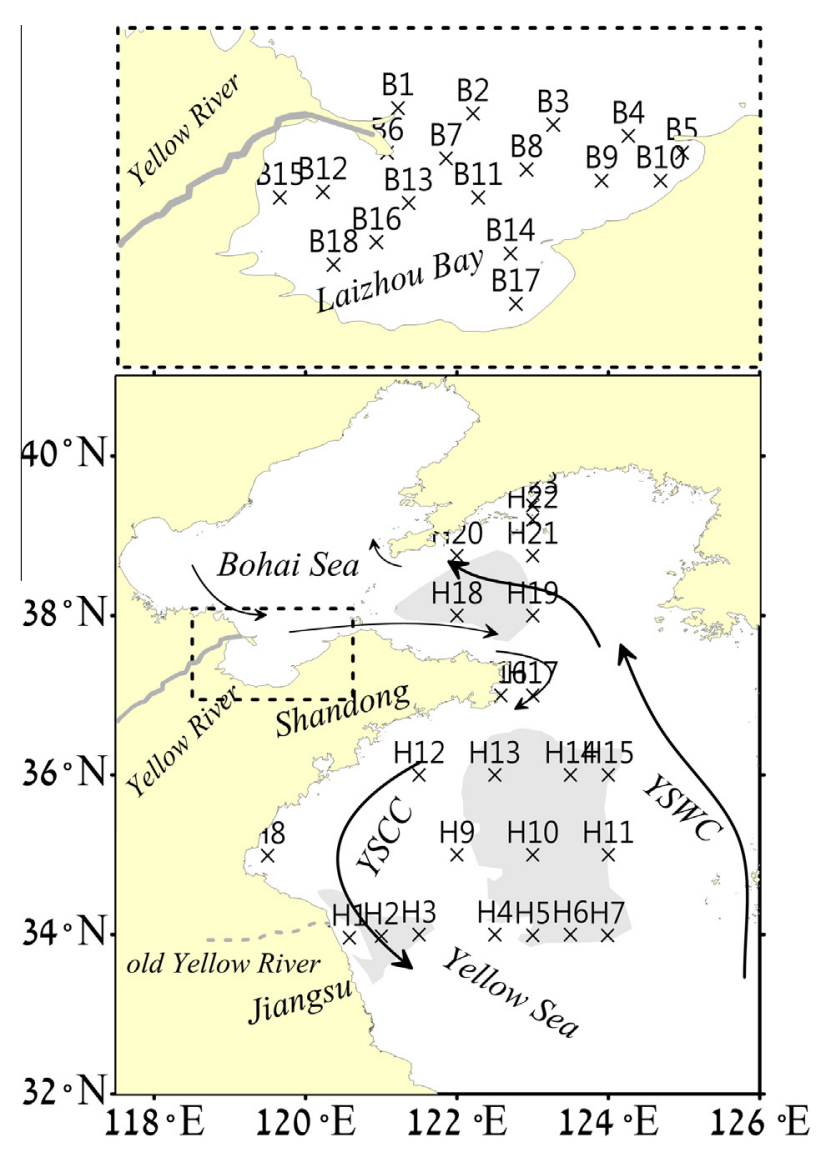

Fig. 1. Map of sampling sites in the Southern Bohai Sea (B1-B18) and the Northern Yellow Sea (H18-H23), Southern Yellow Sea (H1-H17). (YSCC: Yellow Sea coastal current; YSWC: Yellow Sea warm current). by addition of activated copper. The free lipids were fractionated using silica gel-alumina column chromatography $(50 \mathrm{~mm} * 5 \mathrm{~mm}$ i.d.). The $n$-alkanes were eluted with $20 \mathrm{ml}$ of hexane and the $n$ alkanols and sterols were eluted using $20 \mathrm{ml}$ of $20 \%$ ethyl acetate in hexane. Prior to GC/MS analyses, the alkanols and sterols fractions were derivatized with acetic anhydride/pyridine $(1: 1 \mathrm{v} / \mathrm{v})$.

GC/MS analyses were carried out using a Finnigan Platform II mass spectrometer coupled to a HP 6890 GC and a HP-5 fused silica capillary column $\left(50 \mathrm{~m}^{*} 0.32 \mathrm{~mm} * 0.25 \mu \mathrm{m}\right)$. Helium was used as the carrier gas $\left(1.0 \mathrm{ml} \mathrm{min}^{-1}\right)$. Temperature was programmed at $70{ }^{\circ} \mathrm{C}$ for $5 \mathrm{~min}$, then at $3{ }^{\circ} \mathrm{C} \mathrm{min}^{-1}$ to $290{ }^{\circ} \mathrm{C}$, and held for $30 \mathrm{~min}$ at $290{ }^{\circ} \mathrm{C}$. Calibration curves for the compounds were created using standard solutions of $n$-alkanes (even carbon number of $n \mathrm{C} 10-$ $n C 36)$ and sterols ( $5 \beta$-cholestan-3 $\beta$-ol, cholest-5-en-3 $\beta$-ol, 24Methylcholest-5-en-3 $\beta$-ol, 24-Methylcholest-5, 22-dien-3 $\beta$-ol, 24 -Ethylcholest-5-en-3 $\beta$-ol, 24-Ethylcholest-5, 22-dien-3 $\beta$-ol). All standards used were purchased at AccuStandard Inc. Component assignment was performed by comparing the retention times of the peaks with those of the standards. For quantification, peak area was multiplied by the response factor for each compound present in the calibration curve. Any odd-numbered carbon $n$-alkane (and derivatized alkanol) were quantified with the average response factor of adjacent $n$-alkenes as their standards were not available.

\subsection{Total organic carbon (TOC) analysis}

Samples for TOC analysis were acidified with dilute $\mathrm{HCl}$ before analysis to remove carbonates, subsequently rinsed with deionized water three times before drying overnight at $60^{\circ} \mathrm{C}$. The samples were weighed before and after the $\mathrm{HCl}$ treatment to obtain carbonate contents. Contents of TOC were determined on a CHNS Vario E1 III elemental analyzer. Replicate analysis of one sample $(n=7)$ gave a precision of $\pm 0.02 \mathrm{wt} \%$ for TOC.

\section{4. $P C A$}

Un-normalized concentrations of the 35 compounds ( $n \mathrm{C} 15-$ $n$ C33 $n$-alkanes, $n \mathrm{C} 14 \mathrm{OH}-\mathrm{C} 30 \mathrm{OH}$ with even-number $n$-alkanols and 6 sterols) of the 41 sediment samples were used in the PCA. SPSS (SPSS Inc., Chicago) was applied to extract the principal components (PCs) based on the correlation matrix. The PCs that eigenvalues $>1$ were considered to be factors for further discussion.

\section{Results}

\section{1. n-alkanes}

The concentrations of the total $n$-alkanes $(n \mathrm{C} 15-n \mathrm{C} 33)$ varied from 300 to $3100 \mathrm{ng} / \mathrm{g}$ (dry weight, the same below). The concentrations of the total $n$-alkanes in this study were compared to the data reported for coastal or marginal seas of China, such as the Pearl River Estuary and the Northern South China Sea (160$2670 \mathrm{ng} / \mathrm{g}, n=38$ ) (Hu et al., 2009b), the Yangtze River Estuary and the East China Sea (70-3000 ng/g) (Xing et al., 2011), but slightly lower than the Bohai Bay and the Bohai Sea (390$4900 \mathrm{ng} / \mathrm{g}, n=55$ ) (Hu et al., 2009a), the area off Northeastern Taiwan Island (Jeng et al., 2003). Spatially, the highest value was found at the site H13 located in the open-sea area of SYS and the higher values were found at the sites H10, H11, H14 and H15 in nearby areas. Other sites with high concentration were detected in the center of NYS (H18 and H19, $2850 \mathrm{ng} / \mathrm{g}$ and $2480 \mathrm{ng} / \mathrm{g}$ ) (Fig. 2A). It is consistent with the two centers of YS served as the main sink for fine particles and contained more preserved OM (Hu et al., 2013). The concentrations of $n$-alkanes were 

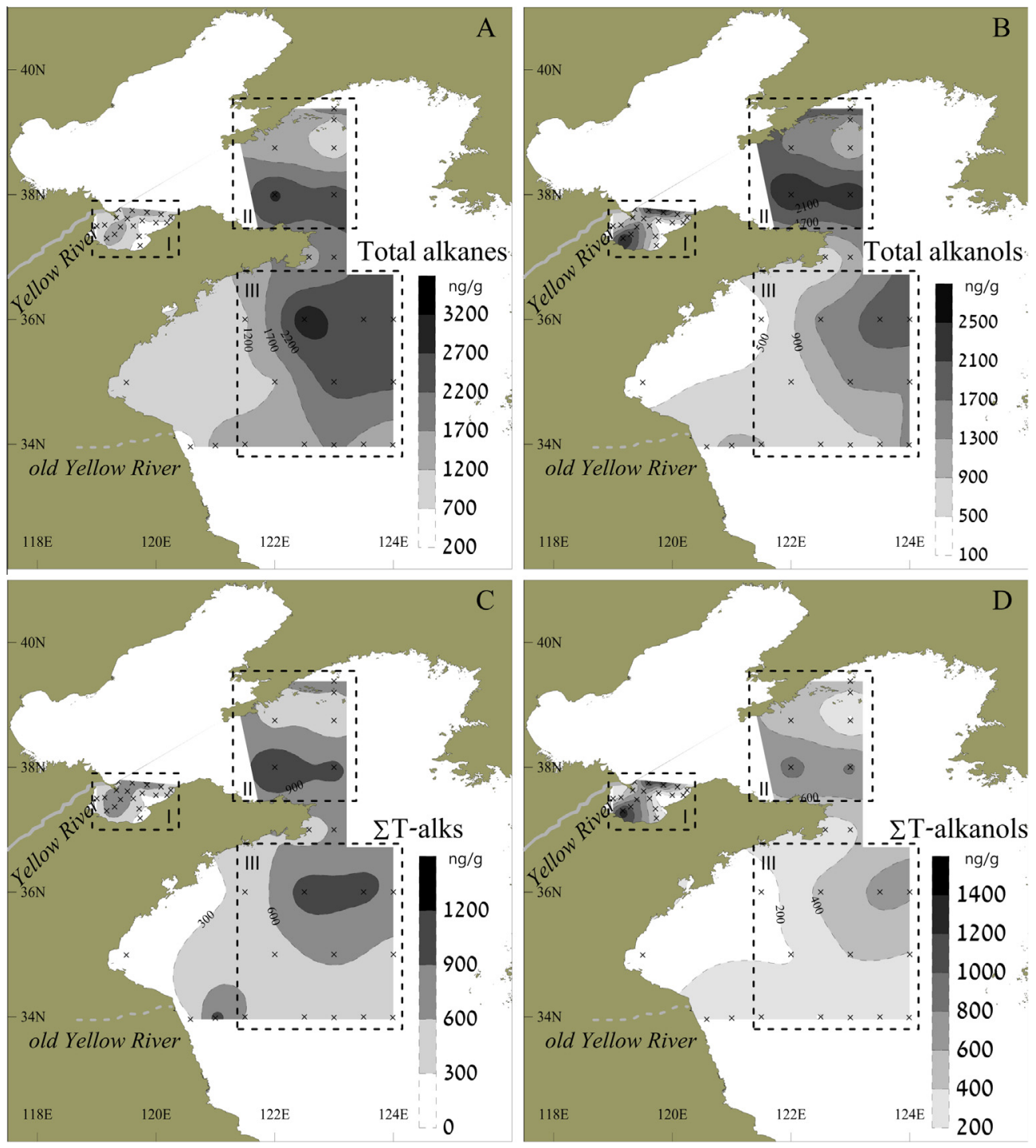

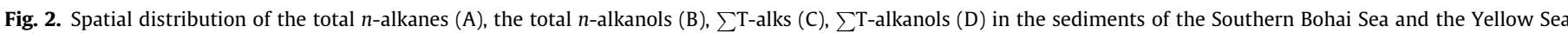
(Area I: SBS, Area II: NYS, Area III: SYS).

299-1737 ng/g $(1011 \pm 421 \mathrm{ng} / \mathrm{g})$ in the sediments in SBS, lower than those in YS $(542-3100 \mathrm{ng} / \mathrm{g}, 1733 \pm 703 \mathrm{ng} / \mathrm{g})$.

According to the composition of $n$-alkanes in this study, two different profiles were apparent, as illustrated in Fig. $3 \mathrm{~A}$ and B for samples B3 and H13 as representative: (i) unimodal $n$-alkane distribution with strong odd to even carbon number predominance and maximum at $n \mathrm{C} 29$, occurred mainly in SBS; (ii) bimodal molecular distribution with maxima at $n \mathrm{C} 17$ and $n \mathrm{C} 29$ or $n \mathrm{C} 31$, respectively, mainly found in YS. n-Alkanes are commonly used to obtain a broad and directly overview of hydrocarbon sources ranging from terrestrial vascular plant material to marine-derived phytoplankton or algae. Generally, the short-chain n-alkanes ( $n \mathrm{C} 15-n \mathrm{C} 20$, SCalks) (the $n \mathrm{C} 17$ homologue is dominant) are presumed to originate from phytoplankton or algae (Meyers and Ishiwatari, 1993; Meyers, 2003), while the long-chain $n$-alkanes ( $n \mathrm{C} 26-n \mathrm{C} 31$, LCalks) such as the $n \mathrm{C} 27, n \mathrm{C} 29$ and $n \mathrm{C} 31$ compounds are mainly produced by terrestrial plants (Logan and Eglinton, 1994). A correlation analysis was performed to reveal internal relationship of these $n$-alkanes. Then the $n$-alkanes were combined into three groups according to their correlation coefficients, and each supposed to be similar potential sources. As shown in Table 1, the $n$-alkanes in the range of $n \mathrm{C} 26-n \mathrm{C} 31$ were correlated $\left(r^{2}=0.51-0.95\right)$, and therefore combined as one group from terrestrial vascular plants. Similarly, there were strong correlations between two of SCalks, showing a linear relationship when cross-plotted $\left(r^{2}=0.56-0.94\right)$. It was characteristic of marine lipid biomarkers. The carbon preference index (CPI) of the LCalks, ratio of $(n \mathrm{C} 27+n \mathrm{C} 29+n \mathrm{C} 31) /(n \mathrm{C} 26+n \mathrm{C} 28+n \mathrm{C} 30)$, ranged from 4 to 13, further supporting evidence that the LCalks were derived from fresh higher plant waxes (Table 2, Schefuß et al., 2003; Wang et al., 2003). The origins of SCalks, in contrast, characterized by $n \mathrm{C} 17$ homologue predominance and low CPIs (ratio of $(n \mathrm{C} 15+n \mathrm{C} 17+n \mathrm{C} 19) /(n \mathrm{C} 16+n \mathrm{C} 18+n \mathrm{C} 20))$ from 0.3 to 1.1 $(0.72 \pm 0.23)$ in the study area, were in agreement with the input from phytoplankton (Bouloubassi et al., 2001).

\section{2. n-Alkanols}

$n$-Alkanols in the study areas ranged from $n \mathrm{C} 140 \mathrm{OH}$ to $n \mathrm{C} 30 \mathrm{OH}$ with a strong even over odd carbon number predominance. In most case, odd carbons $n$-alkanols were not detected because of too low concentration in this study. The total $n$-alkanol concentrations ranged from 100 to $2560 \mathrm{ng} / \mathrm{g}$. The lowest and highest values were both recorded in the coastal area of SBS (B18, $2560 \mathrm{ng} / \mathrm{g})$. The 

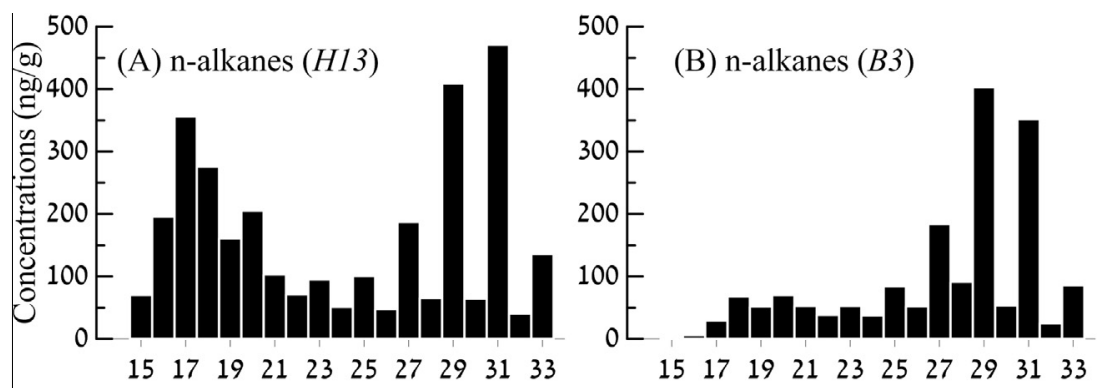

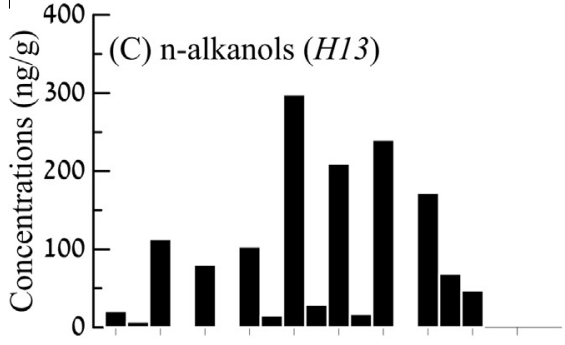

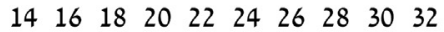

Carbon number

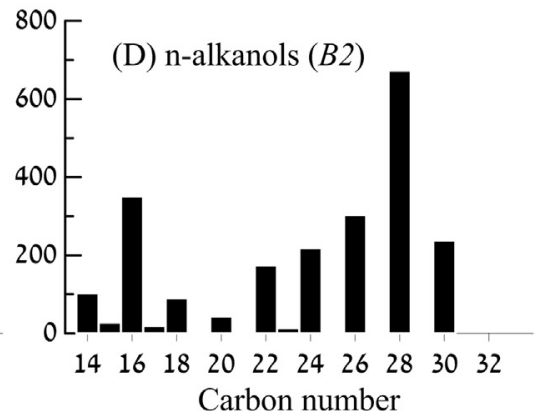

Fig. 3. Different profiles of $n$-alkanes and $n$-alkanols composition from the selected samples in the Southern Bohai Sea and the Yellow Sea.

Table 1

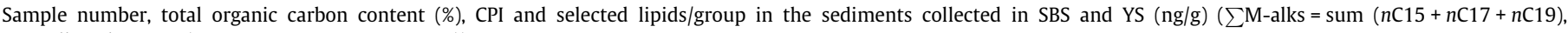
$\sum \mathrm{M}$-alkanols $\left.=\operatorname{sum}(n \mathrm{C} 14 \mathrm{OH}+n \mathrm{C} 16 \mathrm{OH}+n \mathrm{C} 18 \mathrm{OH})\right)$.

\begin{tabular}{|c|c|c|c|c|c|c|c|c|c|c|}
\hline Location & $\sum \mathrm{T}$-alks & $\sum \mathrm{M}$-alks & $\sum$ T-alkanols & $\sum \mathrm{M}$-alkanols & $27 \Delta^{5}$ & $28 \Delta^{5,22}$ & $29 \Delta^{5} \& 29 \Delta^{5,22}$ & CPISCalk & CPILCalk & TOC \\
\hline $\mathrm{H} 1$ & 261 & 91 & 328 & 260 & 60 & 1441 & 60 & 1.1 & 11.2 & 0.30 \\
\hline $\mathrm{H} 2$ & 1019 & 51 & 375 & 14 & 447 & 1210 & 74 & 0.8 & 13.6 & 0.34 \\
\hline H3 & 594 & 222 & 335 & 23 & 28 & 1112 & 55 & 0.9 & 12.2 & 0.41 \\
\hline $\mathrm{H} 4$ & 408 & 379 & 192 & 94 & 836 & 723 & 154 & 1.1 & 4.2 & 0.48 \\
\hline H5 & 465 & 393 & 303 & 161 & 426 & 544 & 127 & 0.8 & 4.0 & 0.5 \\
\hline H6 & 498 & 291 & 239 & 158 & 904 & 745 & 182 & 0.9 & 5.2 & 0.78 \\
\hline H7 & 308 & 321 & 216 & 945 & 418 & 296 & 81 & 1.0 & 5.0 & 0.68 \\
\hline H8 & 206 & 289 & 59 & 256 & 827 & 835 & 182 & 0.8 & 4.8 & 0.41 \\
\hline H9 & 461 & 182 & 190 & 119 & 1043 & 855 & 170 & 0.8 & 6.4 & 0.21 \\
\hline $\mathrm{H} 10$ & 652 & 478 & 410 & 221 & 1437 & 1105 & 269 & 0.9 & 4.8 & 0.34 \\
\hline H11 & 466 & 647 & 390 & 132 & 920 & 723 & 168 & 0.9 & 4.1 & 0.74 \\
\hline H12 & 341 & 219 & 112 & 116 & 735 & 637 & 132 & 0.8 & 5.3 & 0.34 \\
\hline H13 & 1067 & 587 & 460 & 215 & 976 & 733 & 222 & 0.9 & 6.3 & 0.72 \\
\hline H14 & 954 & 433 & 672 & 245 & 1734 & 889 & 223 & 0.8 & 5.9 & 0.97 \\
\hline H15 & 856 & 438 & 617 & 248 & 1576 & 794 & 196 & 0.9 & 5.9 & 0.95 \\
\hline H16 & 454 & 307 & 268 & 117 & 1850 & 462 & 101 & 0.9 & 6.9 & 0.28 \\
\hline H17 & 627 & 462 & 349 & 360 & 1055 & 1006 & 169 & 0.9 & 6.6 & 0.38 \\
\hline H18 & 1173 & 406 & 899 & 406 & 1285 & 1738 & 337 & 1.0 & 5.9 & 0.8 \\
\hline H19 & 972 & 415 & 850 & 829 & 3498 & 1532 & 356 & 1.0 & 6.2 & 0.82 \\
\hline $\mathrm{H} 20$ & 499 & 199 & 451 & 488 & 1177 & 753 & 184 & 1.0 & 7.1 & 0.5 \\
\hline $\mathrm{H} 21$ & 372 & 95 & 170 & 485 & 495 & 240 & 52 & 0.9 & 7.2 & 0.4 \\
\hline $\mathrm{H} 22$ & 563 & 66 & 341 & 398 & 951 & 980 & 139 & 0.8 & 6.3 & 0.46 \\
\hline $\mathrm{H} 23$ & 873 & 424 & 656 & 530 & 2943 & 1822 & 299 & 1.0 & 6.0 & 0.50 \\
\hline B1 & 514 & 81 & 478 & 125 & 181 & 188 & 159 & 0.5 & 7.2 & 0.21 \\
\hline B2 & 896 & 133 & 1214 & 544 & 751 & 1042 & 288 & 0.7 & 6.8 & 0.41 \\
\hline B3 & 938 & 81 & 1119 & 584 & 761 & 1248 & 330 & 0.6 & 5.5 & 0.45 \\
\hline B4 & 633 & 77 & 636 & 434 & 510 & 826 & 191 & 0.5 & 5.5 & 0.33 \\
\hline B5 & 341 & 64 & 202 & 504 & 1592 & 906 & 221 & 0.5 & 3.8 & 0.12 \\
\hline B6 & 641 & 22 & 464 & 13 & 139 & 16 & 118 & 0.4 & 6.4 & 0.17 \\
\hline B7 & 708 & 31 & 634 & 285 & 431 & 597 & 167 & 0.5 & 5.8 & 0.26 \\
\hline B8 & 230 & 19 & 45 & 60 & 373 & 289 & 95 & 0.3 & 4.4 & 0.09 \\
\hline B9 & 286 & 22 & 132 & 228 & 626 & 657 & 131 & 0.4 & 4.8 & 0.11 \\
\hline B10 & 307 & 43 & 185 & 273 & 645 & 502 & 146 & 0.6 & 5.2 & 0.17 \\
\hline B11 & 554 & 28 & 490 & 191 & 267 & 362 & 141 & 0.4 & 6.3 & 0.16 \\
\hline B12 & 644 & 53 & 431 & 208 & 339 & 340 & 143 & 0.5 & 8.1 & 0.16 \\
\hline B13 & 789 & 75 & 879 & 413 & 472 & 675 & 240 & 0.4 & 6.8 & 0.33 \\
\hline B14 & 427 & 37 & 358 & 345 & 1069 & 621 & 152 & 0.5 & 6.3 & 0.16 \\
\hline B15 & 341 & 19 & 253 & 210 & 252 & 278 & 85 & 0.4 & 4.8 & 0.20 \\
\hline B16 & 804 & 65 & 945 & 509 & 682 & 677 & 237 & 0.5 & 6.5 & 0.34 \\
\hline B17 & 152 & 11 & 800 & 233 & 145 & 109 & 49 & 0.4 & 4.0 & 0.05 \\
\hline B18 & 644 & 102 & 1365 & 715 & 1464 & 1076 & 291 & 0.7 & 4.5 & 0.25 \\
\hline
\end{tabular}


Table 2

Selected biomarker grouping, internal correlation, and main sources of biomarkers in SBS and YS.

\begin{tabular}{|c|c|c|c|}
\hline Group/biomarker & Correlation $\left(R^{2}\right)$ & Main source & Refs. \\
\hline LCalks & $0.51-0.95$ & Epicuticular plant waxes & Eglinton and Hamilton (1967) \\
\hline SCalks & $0.56-0.94$ & Microalgae, bacteria & Bouloubassi et al. (2001) \\
\hline LCalkanols & $0.65-0.80$ & Epicuticular plant waxes & Eglinton and Hamilton (1967) \\
\hline MCalkanols & $0.57-0.92$ & Macrophytes, seagrass & Lü and Zhai (2006) \\
\hline SCalkanols & 1 & Microalgae, bacteria & Xu and Jaffé (2007) \\
\hline Coprostanol & l & Sewage & Leeming et al. (1996) \\
\hline Brassicasterol & l & Mainly from diatoms & Volkman (2003), Hernandez et al. (2008) \\
\hline Sitosterol, stigmasterol & $0.63-0.70$ & Plant-derived sterol or microalgae & Gagosian et al. (1983), Volkman (2003) \\
\hline
\end{tabular}

MCalkanols: mid-chain alkanols ( $n \mathrm{C} 20 \mathrm{OH}-n \mathrm{C} 24 \mathrm{OH})$.

concentrations were slightly higher in NYS $(920-2500 \mathrm{ng} / \mathrm{g}, n=8)$ than those in SYS (400-2000 ng/g, $n=15$ ) (Fig. 2B).

According to the results of variation in concentration, the $n$-alkanols also can be divided into three categories in this study (Table 1 ). Similar to $n$-alkanes, higher plant waxes tend to mainly contain the long-chain alkanols ( $>n \mathrm{C} 24 \mathrm{OH}$, LCalkanols). By contrast, the occurrence of short-chain alkanols (SCalkanols) in the range $n \mathrm{C} 14 \mathrm{OH}-n \mathrm{C} 190 \mathrm{H}$ is indicator of marine sources (Xu and Jaffé, 2007). $n \mathrm{C} 20 \mathrm{OH}, n \mathrm{C} 22 \mathrm{OH}$ and $n \mathrm{C} 24 \mathrm{OH}$ were widely detected in this study and defined as aquatic macrophytes or seagrass (Lü and Zhai, 2006).

Typical $n$-alkanol composition profiles were shown in Fig. $3 \mathrm{C}$ and D. In SBS, molecular distribution had maximum at $n \mathrm{C} 28 \mathrm{OH}$ and dominated by the LCalkanols with percentages of $50 \pm 8 \%$. It was consistent with the $n$-alkane composition in SBS. $n$-alkanols showed a bimodal pattern in YS: mid-chain homologues maximized at $n \mathrm{C} 22 \mathrm{OH}$ while long-chain ones maximized at $n \mathrm{C} 26 \mathrm{OH}$ or $n \mathrm{C} 280 \mathrm{H}$. Of particular note was that the $n$-alkanol profiles in the several sediments from the coast of Jiangsu provinces and NYS had predominant $n \mathrm{C} 16 \mathrm{OH}$ and $n \mathrm{C} 18 \mathrm{OH}$ or $n \mathrm{C} 22 \mathrm{OH}$. It can be explained by the coast areas suffered an outbreak of green algae and seagrass recent years (Shi and Wang, 2009). The investigations indicated the possible relationships between the troublesome association of seagrass with the recent rapid expansion of the edible seaweed P. yezoensis aquaculture in the Jiangsu province of China and the culture method and seasonal harvesting procedures (Shi and Wang, 2009; Liu et al., 2009). Here, Raq is defined as the relative proportion of abundant hydrocarbons derived from terrestrial plants and macrophytes using the ratio of $(n \mathrm{C} 26 \mathrm{OH}+$ $n \mathrm{C} 28 \mathrm{OH}) /(n \mathrm{C} 22 \mathrm{OH}+n \mathrm{C} 24 \mathrm{OH})$. The Raq showed an overall decreasing from SBS (1.6-3.6) to NYS (0.8-1.3) and SYS (0.6-1.3). The results indicate a predominant terrestrial contribution in SBS, while a mixed terrestrial and macrophytes input in YS.

\subsection{Sterols}

A series of C27-C29 sterols were detected in the sediments with the total concentrations ranging from 100 to $5500 \mathrm{ng} / \mathrm{g}$ $(1700 \pm 1100 \mathrm{ng} / \mathrm{g})$ in this study. Sterols have been proven to be specific biomarkers for a particular organism class, and their composition and abundances can also provide valuable information on OM origin. In this study, the marine-derived sterol (cholesterol and brassicasterol) dominated the total sterols both in SBS and YS, showing the following order of sterol abundance: cholesterol $>$ brassicasterol $>$ sitosterol $>$ campesterol $\approx$ stigmasterol.

Cholesterol and brassicasterol together accounted for 64-94\% $(86 \pm 10 \%)$ of the total sterols in the studying areas. The composition of sterols in the sediments suggests that contributions from the terrestrial sterols were only of minor importance.

Coprostanol ( $5 \beta$-cholestan-3 $\beta$-ol) is a C27 sterol formed from the biohydrogenation of cholesterol in the gut of most higheranimals and birds, and this compound has frequently been used as a biomarker for the presence of human faecal matter in aquatic environment (Bethell et al., 1994; Bull et al., 2002). In coastal environment, this compound has frequently been used as a biomarker to determine pollutant loading from sewage (Leeming et al., 1996; Mudge and Norris, 1997). The higher concentrations of coprostanol were found at B18 and B16 (440 ng/g and $104 \mathrm{ng} / \mathrm{g}$ ) in the coastal area of Laizhou Bay (LZB), decreased seaward, rapidly in the first $5 \mathrm{~km}$ and then kept stable in the open sea $(<40 \mathrm{ng} / \mathrm{g})$. The other C27-sterol cholesterol (cholest-5-en-3 $\beta$-ol, 27 $\Delta^{5}$ ) was detected but in high concentration ( $748 \pm 615 \mathrm{ng} / \mathrm{g}$ ), nearly 8 times higher than that of coprostanol in an average in the sediments. Cholesterol is a lipid which is produced by the animal liver and also normally synthesized by a wide variety of phytoplankton and zooplankton in marine environment (Volkman, 1986; Volkman et al., 1998). The higher concentrations (>1000 ng/g) presented in the coastal area (B5, B14, B18 and H16, H17, H20, H23) and in the open sea areas of NYS and SYS (H9, H10, H14, H15, H18 and H19). High concentrations of cholesterol at both the coastal areas and the open sea areas suggest a mixed input. One of the commonly used proxies to evaluate the relative importance of sewage discharge for cholesterol is coprostanol/cholesterol ratio. Generally, raw untreated sewage typically has a ratio of $2-10$. As the wastewater is dispersed in the environment, the ratio will decrease as additional cholesterol from marine organism is encountered. Quemeneur and Marty (1992) have suggested that sediment samples with a coprostanol/cholesterol greater than 0.2 may be considered as significant input from sewage. In this study, the ratios $>0.2$ (only B5, B14 and B18) were all located along the coastline of LZB. The sediment samples were characterized by a low ratio $(<0.2)$ and concurrent with increasing concentrations of cholesterol in YS, suggesting marine-derived cholesterol was an important contribution in YS.

Two C28 sterol compounds, campesterol (24-Methylcholest-5en-3 $\beta$-ol, $28 \Delta^{5}$ ) and brassicasterol (24-Methylcholest-5, 22-dien$\left.3 \beta-o l, 28 \Delta^{5,22}\right)$, were detected with mean concentrations $22 \pm 13 \mathrm{ng} / \mathrm{g}$ and $679 \pm 437 \mathrm{ng} / \mathrm{g}$, respectively. For all sediment samples, campesterol had minor amount with only constituted $1-4 \%$ of the total measured sterols. Brassicasterol was reported to be a more useful specific biomarker for some diatoms (Volkman, 2003; Hernandez et al., 2008). High concentrations of brassicasterol in sites from coastal areas support that the sediments in the coastal areas of Jiangsu Provinces and Shandong Provinces received more diatoms input (Table 1 ), which was in agreement with the observation from Di et al. (2013) and Liu et al. (2009).

C29 sterols are traditionally used as biomarkers of terrestrial lipid inputs, such as sitosterol (24-Ethylcholest-5-en-3 $\beta$-ol, $29 \Delta^{5}$ ) and stigmasterol (24-Ethylcholest-5, 22-dien-3 $\beta$-ol, $29 \Delta^{5,22}$ ). However, Volkman (2003) and more recently Rampen et al. (2009) showed that these compounds are also present in several groups of microalgae. Sitosterol was more abundant than stigmasterol, $125 \pm 58 \mathrm{ng} / \mathrm{g}$ and $25 \pm 13 \mathrm{ng} / \mathrm{g}$, respectively in this study. 


\section{Discussion}

\subsection{Spatial distribution of TOM under the specific depositional} hydrodynamic setting

The terrestrial $n$-alkanes $(n \mathrm{C} 27+n \mathrm{C} 29+n \mathrm{C} 31)\left(\sum \mathrm{T}\right.$-alks $)$ are observed with the most abundant lipid compounds in sediment, and have been widely reported as being derived from terrestrial higher plants. Thus, the $\sum$ T-alks are often useful for tracing distribution and transport information of TOM in watershed and aquatic environments (Prahl et al., 1994; Fernandes and Sicre, 2000; Seki et al., 2006; Schmidt et al., 2010). In this study, the spatial distributions of $\sum \mathrm{T}$-alks and other terrestrial lipid biomarkers, the terrestrial $n$-alkanols $\left(n \mathrm{C} 26 \mathrm{OH}+n \mathrm{C} 28 \mathrm{OH}+n \mathrm{C} 30 \mathrm{OH}, \quad \sum\right.$ T-alkanols $)$, sitosterol and stigmasterol, reveal that the shelf region has three isolated areas of TOM sink: the inner of LZB, the centers of NYS and SYS, respectively (Fig. 2C and D).

The contribution of OM in the sediments of the inner of LZB were dominated by TOM input, as indicated by the higher ratios of $(n \mathrm{C} 27+n \mathrm{C} 29+n \mathrm{C} 31) /(n \mathrm{C} 15+n \mathrm{C} 17+n \mathrm{C} 19)$, supposed to be related to large sediment discharge from the Yellow River. (1) Qiao et al. (2010) proposed that a large amount of the Yellow River-derived sediments were transported southward off the river mouth and trapped in the southern LZB, before driven offshore along the southern bay coast across the Bohai Strait. (2) Hu et al. (2013) also pointed out that the Yellow River estuary and its adjacent SBS could serve as the main sink for the fluvial-derived OM based on sediment grain size parameters and molecular indices. In this study, such a scenario is also reflected by the present data of $\sum$ T-alks (Fig. 4A), suggesting the accumulation of terrestrial $n$ alkanes in SBS is more regulated by the fate of the Yellow Riverderived sediments. It is consistent with result that $n$-alkanes are more abundant in the fine particles ( $<32 \mu \mathrm{m}$ fractions), e.g. the fine particles ( $<32 \mu \mathrm{m}$ fractions), accounting for $45 \%$ of total suspended solid mass, contained $78 \%$ of the total $n$-alkanes discharge from the Yellow River (Zhang et al., 2009). In comparison, the concentrations of $n$-alkanes in the sediments from LZB were low than those of the suspended particles from the low reaches of the Yellow River (940-6540 ng/g) (Zhang et al., 2009). The sediment discharge from the Yellow River has not brought out continuous enrichment of TOM in the sediments of LZB, but in contrast the settlement of large flux of the coarse sediments and the fine-sediment resuspension could lead to a dilution effect for the concentration levels of these compounds at the river mouth.

Fine-grained sediments from LZB are resuspended, redistributed and constrained to the center of NYS, yielding the highest clay and TOC contents (Yang and Liu, 2007; Hu et al., 2013). The expected higher $\sum$ T-alks concentrations were observed in NYS compared to LZB in this study. Controlled by spatial distribution pattern of the sediments (especially the fine-grain sediments) in NYS, TOC contents are highly correlated with sediment grain size, which have confirmed by numerous studies (Hu et al., 2011, 2013; Xing et al., 2011). Meanwhile, highly significant correlation $\left(R^{2}=0.76, p<0.05\right)$ is found between $\sum \mathrm{T}$-alks and TOC in this study (Fig. 4B), suggesting terrestrial $n$-alkane inputs associated with the sediment after long-range transport were considerable.

At present the sediments from the Yellow River do not into SYS directly, but they are still considered as the major sediment sources to SYS, based intuitively on the huge sediment discharge from the river (Milliman and Meade, 1983; Dong et al., 2011). In this study, $\sum \mathrm{T}$-alks concentrations in the sediments from the central SYS were inconsistent relationship with TOC $\left(R^{2}=0.30\right.$, see Fig. 4C), although the TOC still had a close correlation with the median diameter of grain sizes in those sediments ( $\mathrm{Hu}$ et al., 2011). Dong et al. (2011) pointed out sediments deposited in the
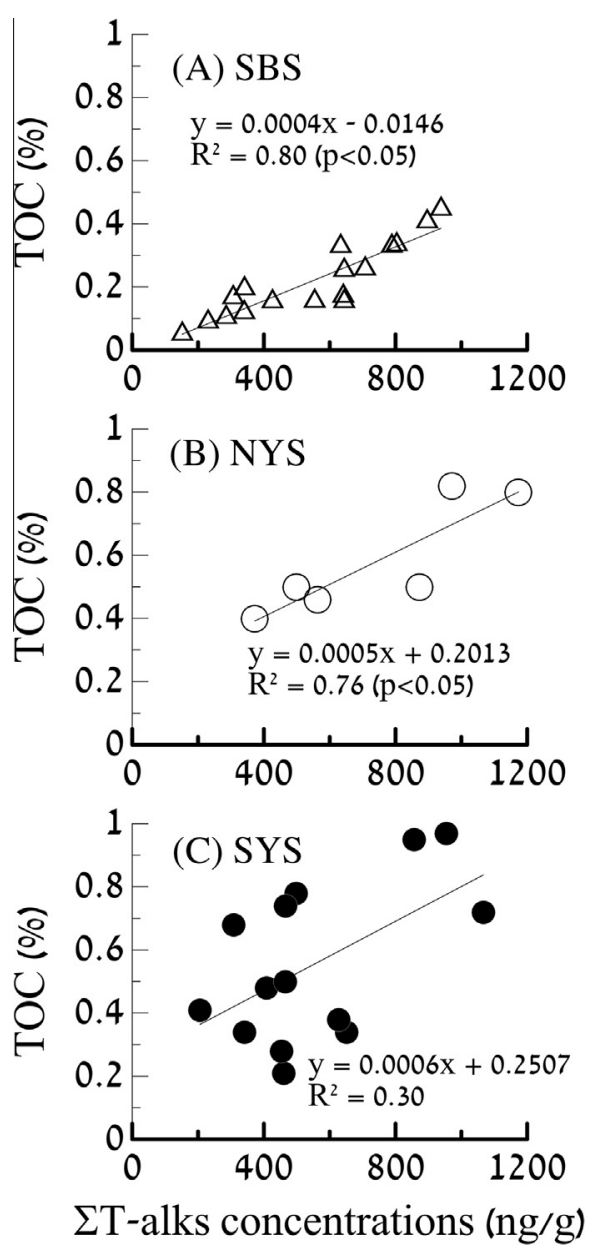

Fig. 4. Correlations of $\sum \mathrm{T}$-alks concentrations and TOC contents in the sediments of SBS (A), NYS (B) and SYS (C) (H1-H3 and H8 is NOT included).

central muddy patch likely come from its surrounding waters, e.g. sediments from the Yellow River, the old Yellow River underwater delta, and the Korean peninsula all can be transported to the central YS, and those TOM from surrounding mixed land-based sediments to the central mud deposits in SYS could be enhanced due to the convergence depositional setting for fine-grained sediments (Hu et al., 2013). In this study, carbon number maxima of LCalks were $n$ C29 in LZB and $n$ C 31 in SYS, respectively. The dominance of C27 and C29 n-alkanes reflects a plant wax signature typical of shrubs and woody plants, while C31 n-alkane is more abundant found in grasses (Bush and McInerney, 2013). The carbon number maxima shifted from $n \mathrm{C} 29$ to $n \mathrm{C} 31$ in SYS reflecting the contribution of terrestrial $n$-alkanes derived from different sources. In addition, long-range atmospheric transport is an important input path for sediment in SYS, resulting in a potential contribution of TOM to OM pool (Zhang et al., 1992). Therefore, although the provenance of sediment in SYS was not yet clear, the terrestrial $n$-alkanes from the Yellow River discharge had a relatively small contribution in SYS.

PCA is a useful data analysis technique for examining factors to reveal relationships and patterns within datasets. In this study, the datasets for PCA contain all individual lipid compounds, and two PCs are only responsible for $53 \%$ of the total variance. PCA does not provide a clear discrimination between terrestrial compounds and marine-derived ones largely due to the unique hydrodynamic transport and depositional mechanism of the sediments, which had a pivotal control on the consistent distribution of both TOM and marine-derived organic matter (MOM) in this studying area. 
4.2. Selective preservation of TOM as evidenced by the individual compositional molecular indices

CPIs of LCalks in SYS varied from 4 to 7 (except H1-H3 of 1113 ), which fall in the range of those in SBS and NYS (Table 2). It suggests that degradation did not occur significantly for the terrestrial LCalks after long-range transport, or the LCalks were highly resistant to biochemical degradation with sediment long-range transport. However, it is found that $\sum \mathrm{T}$-alks concentrations increased relative to $\sum \mathrm{T}$-alkanols ones from SBS and NSY to SYS (Fig. 5A). It suggests that the extensive physical reworking disturbance and long-distance transport of fine-grained sediments could lead to a preferential accumulation of land-based constituents, especially these more refractory plant wax $n$-alkanes readily associated with fine silt and clay (Prahl et al., 1994; Bianchi et al., 2002; Hu et al., 2012). Similarly, Poynter and Eglinton (1990) created an index on the base of the LCalks/LCalkanols distribution in sediment
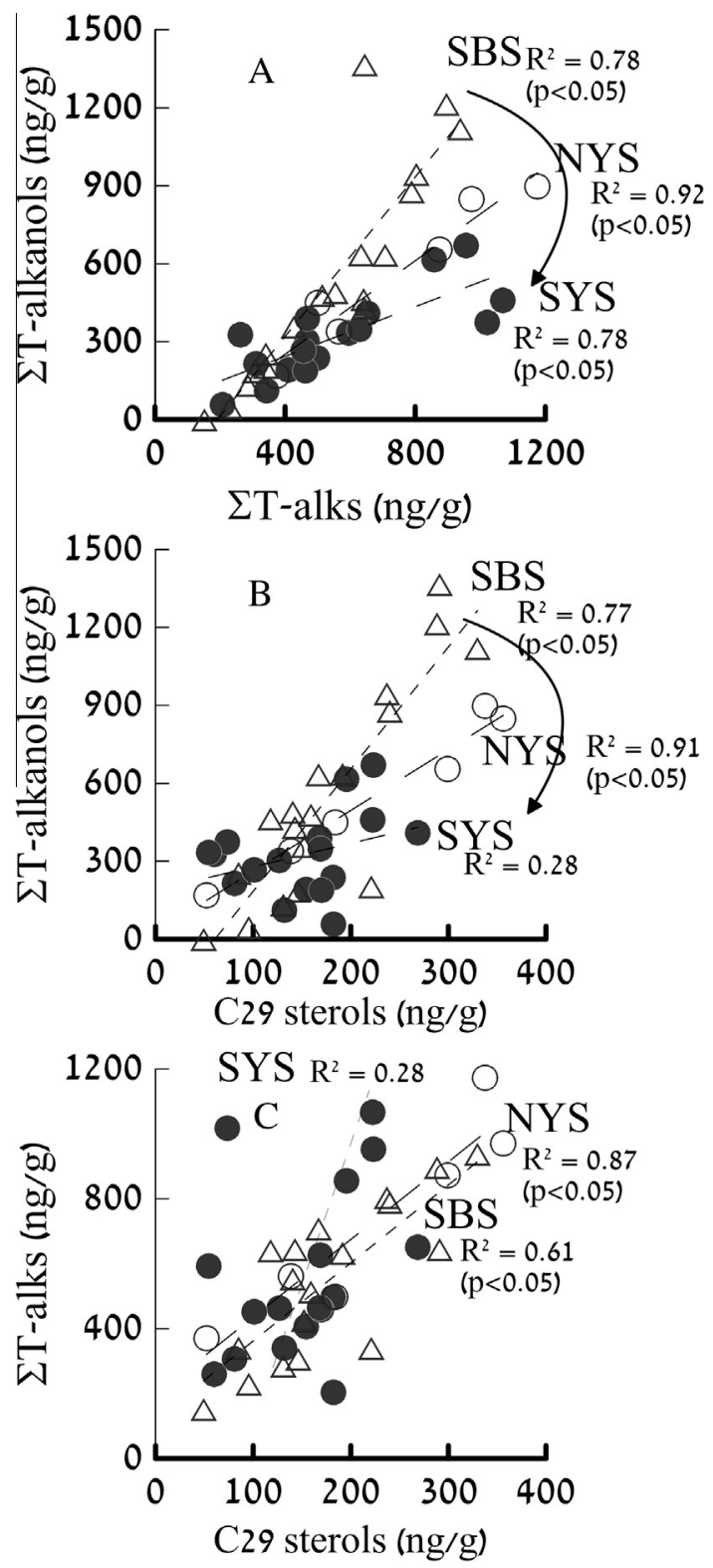

Fig. 5. Correlations between $\sum \mathrm{T}$-alks and $\sum \mathrm{T}$-alkanols (A), $\sum \mathrm{T}$-alkanols and C29 sterols (B), $\sum$ T-alks and C29 sterols (C) and its variation in the sediments of SBS, NYS and SYS (H1-H3 and H8 is NOT included). and they applied this as a proxy for degradation of organic matter on sea floor. Besides, pristane/phytane ratios $(\mathrm{Pr} / \mathrm{Ph})$ were $<0.8$ in this study, the predominance of $\mathrm{Ph}$ over $\mathrm{Pr}$ defined the anoxic conditions in the benthic environment. Redox shift between water-sediment interface may enhance degradation by promoting symbiosis of aerobes and anaerobes. Differently, increased sitosterol and stigmasterol accumulation was observed in SYS compared with those in SBS (Fig. 5B). The correlation coefficients of the sitosterol and stigmasterol with $\sum \mathrm{T}$-alks indicate that these biomarkers were highly related in SBS $\left(R^{2}=0.61, p<0.05\right)$ and NYS $\left(R^{2}=0.87, p<0.05\right)$ (Fig. $\left.5 C\right)$. It can be supported that sitosterol and stigmasterol represented the terrestrial input to the $\mathrm{OM}$ pool in the sediments. While low or weak correlation as observed in SYS $\left(R^{2}=0.28\right)$ indicates that those C29 sterols derived partly from marine products (Fig. 5C). This gives exact evidences that varying C29 sterol concentrations derived from marine productivity rather than degradation.

\subsection{Estimates of TOM vs. MOM}

A qualitative evaluation of the relative contributions of TOM and MOM to the sedimentary OM pool is possible by grouping the lipid biomarkers, e.g. LCalks, LCalkanols are typically associated with terrestrial lipid biomarkers, and marine origin includes SCalks, SCalknols. The concentration ratio of $(n \mathrm{C} 27+n \mathrm{C} 29+n \mathrm{C} 31) /$ $(n \mathrm{C} 15+n \mathrm{C} 17+n \mathrm{C} 19)$ is widely used to assess terrestrial/marinederived hydrocarbons in sediment (Meyers, 1997). In this study, higher ratios $(12 \pm 6$ ) were observed in SBS, whereas those showed a significant decline in YS $(2.2 \pm 1.0)$. The proportion of terrestrial $n$-alkanes to marine-derived $n$-alkanes sharply decreased from SBS to YS. It was likely due to progressively decreasing input of terrestrial $n$-alkanes and increasing production of marine-derived $n$-alkanes in YS. Positive correlation between total $n$-alkanes (and total alkanols) and TOC is observed in the sediments from the studying areas $\left(r^{2}=0.63, p<0.05\right.$ for total $n$-alkanes and $r^{2}=0.30$, $p<0.05$ for total $n$-alkanols) (Fig. 6). It suggests that those two classes of lipids can be good indicators to sources of $\mathrm{OM}$. The ratios of (LCalks + LCalkanols)/(SCalks + SCalknols) ranged from $2.5 \pm 0.7$ (SBS) to $1.2 \pm 0.4$ (YS), the relative contribution of terrestrial lipids was high at SBS but gradually decreased with distance from NYS to SYS (Fig. 7A and B).

Compared with relative contribution of TOM vs. MOM indicated by lipid biomarkers, depositional flux results can give more information in investigating the spatial distribution patterns of OM. By combining TOC data with result of sedimentation rates in a same interpolation gridding density as mass sedimentation rate data, sedimentary TOC burial flux in the studying area can be estimated.

$F i=C i * p i * R i$

where $C i$ is the TOC content in sediment, $p i$ is the dry sediment density $\mathrm{g} / \mathrm{cm}^{3}$, and $R$ is the sedimentation rate $\mathrm{cm} / \mathrm{yr}$ for each sample site after Lim et al. (2007) and Li et al. (2002). In this study, the contents of TOC in the sediments varied from $0.12 \%$ to $0.97 \%$ in the studying area. High contents of TOC (0.68-0.97\%) presented in the central YS, where surface sediments were dominated by finegrained muds (Lim et al., 2006, 2007). However, maximum TOC sedimentary flux was found in SBS and was estimated to be 660,000 ton $/ \mathrm{yr}$ or $110 \mathrm{ton} / \mathrm{km}^{2} / \mathrm{yr}$ in average (the calculated area was $6000 \mathrm{~km}^{2}$ ). The TOC inputs to NYS and SYS were estimated only to be $32 \mathrm{ton} / \mathrm{km}^{2} / \mathrm{yr}$ and $25 \mathrm{ton} / \mathrm{km}^{2} / \mathrm{yr}$, respectively. Annually in 2000-2008, the Yellow River transported about 430,000 ton of OC to the sea (Zhang et al., 2013). In comparison, the Yellow River OM discharge is the important source of TOM to the shelf, and the discharged TOM is mostly trapped in SBS (Fig. 7C). 

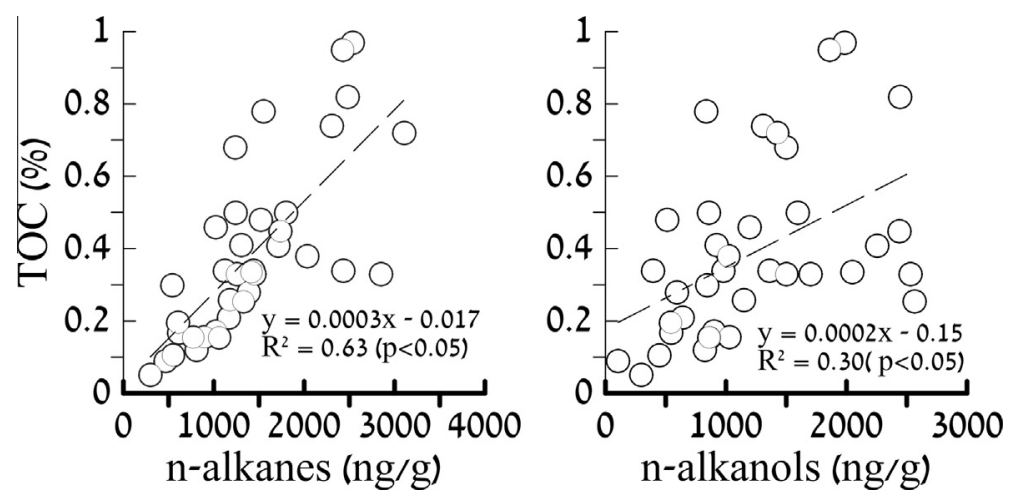

Fig. 6. Correlations of total alkanes (A) and total alkanols (B) with TOC in the sediments of the studying areas (H1-H3 and H8 is NOT included).

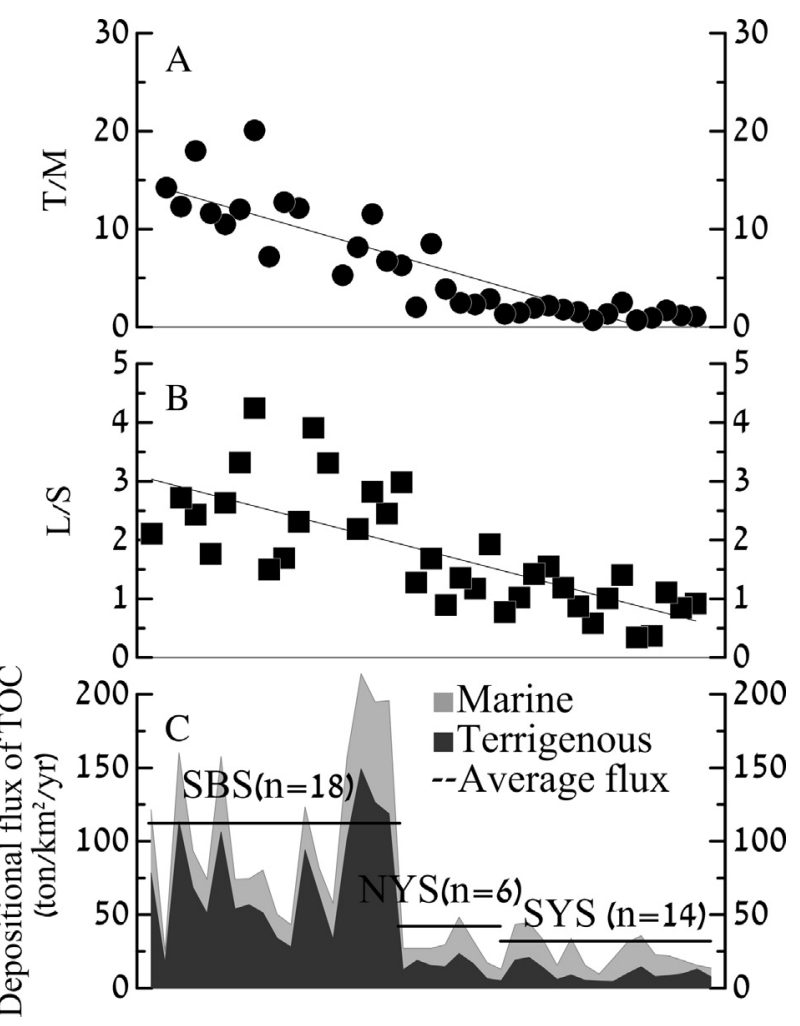

Fig. 7. The relative contributions of $\mathrm{TOM}$ and $\mathrm{MOM}$ indicated by $\mathrm{T} / \mathrm{M}$ : $(n \mathrm{C} 27+n \mathrm{C} 29+n \mathrm{C} 31) /(n \mathrm{C} 15+n \mathrm{C} 17+n \mathrm{C} 19) \quad(\mathrm{A}), \quad \mathrm{L} / \mathrm{S}: \quad$ (LCalks + LCalkanols $) /$ (SCalks + SCalknols) (B) and sedimentary TOC burial flux (ton $/ \mathrm{km}^{2} / \mathrm{yr}$ ) (C) from SBS to NYS and SYS (H1-H3 and H8 is NOT included).

\section{Conclusions}

Supported by the distribution and composition of lipid biomarkers, we could demonstrate that the transport and accumulation of fine-grained sediments, which controlled by interactions between fluvial system and coastal hydrodynamic environment, were responsible for the spatial distribution of those lipids in the sediments of SBS and YS.

Moreover, inconsistent degradations between the different terrestrial compounds were observed during the transport and preservation.

The proportion of terrestrial lipids was high at the river mouth and the inner estuary, decreased with the distance from coast in YS. The Yellow River OM discharge is the important source of TOM to the shelf, but the discharged TOM is mostly trapped in SBS.

\section{Acknowledgements}

This work was partially supported by Shandong Provincial Key Laboratory of Coastal Zone Environmental Processes, YICCAS (Grant No. 201206), Knowledge Innovative Program of CAS (KZCX2-YW-QN210) and Natural Science Foundation of China (NSFC: 41073064). The authors wish to thank the crew of R/V Science I of the Institute of Oceanology, Chinese Academy of Science, for collecting the sediment samples.

\section{References}

Alexander, C.R., DeMaster, D.J., Nittrouer, C.A., 1991. Sediment accumulation in a modern epicontinental-shelf setting: the Yellow Sea. Mar. Geol. 98, 51-72.

Bethell, P.H., Goad, L.J., Evershed, R.P., Ottaway, J., 1994. The study of molecular markers of human activity: the use of coprostanol in the soil as an indicator of human faecal material. J. Archaeol. Sci. 21, 619-632.

Bianchi, T.S., Mitra, S., McKee, B.A., 2002. Sources of terrestrially-derived organic carbon in lower Mississippi River and Louisiana shelf sediments: implications for differential sedimentation and transport at the coastal margin. Mar. Chem. 77, 211-223.

Bouloubassi, I., Fillaux, J., Saliot, A., 2001. Hydrocarbons in surface sediments from the Changjiang (Yangtze river) estuary, East China Sea. Mar. Pollut. Bull. 42, 1335-1346.

Bull, I.D., Lockheart, M.J., Elhmmali, M.M., Roberts, D.J., Evershed, R.P., 2002. The origin of faeces by means of biomarker detection. Environ. Int. 27 (8), 647-654.

Bush, R.T., McInerney, F.A., 2013. Leaf wax $n$-alkane distributions in and across modern plants: implications for paleoecology and chemotaxonomy. Geochim. Cosmochim. Acta 117, 161-179.

Di, B., Liu, D., Wang, Y., Dong, Z., Li, X., Shi, Y., 2013. Diatom and silicoflagellate assemblages in modern surface sediments associated with human activity: a case study in Sishili Bay, China. Ecol. Indicator 24, 23-30.

Dong, L.X., Guan, W.B., Chen, Q., Li, X.H., Liu, X.H., Zeng, X.M., 2011. Sediment transport in the Yellow Sea and East China Sea. Estuar. Coast. Shelf Sci. 93, 248258.

Eglinton, G., Hamilton, R.J., 1967. Leaf epicuticular waxes. Science 156, 1322-1335.

Fernandes, M.A., Sicre, M.A., 2000. The importance of terrestrial organic carbon inputs on Kara Sea shelves as revealed by $n$-alkanes, OC and d13C values. Org. Geochem. 31, 363-374.

Fernandes, M.B., Elias, V.O., Cardoso, J.N., Carvalho, M.I.S., 1999. Sources and fate of $n$-alkanols and sterols in sediments of the Amazon shelf. Org. Geochem. 30, 1075-1087.

Gagosian, R.B., Volkman, J.K., Nigrelli, G.E., 1983. The use of sediment traps to determine sterol sources in coastal sediments off Peru. In: Bjoray, M. et al. (Eds.), Advances in Organic Geochemistry 1981. Wiley, Chichester, pp. 369-379.

Goni, M.A., Monacci, N., Gisewhite, R. Crockett, J., Nittrouer, C., Ogston, A., Alin, S.R. Aalto, R., 2006. Distribution and sources of particulate organic matter in the water column and sediments of the Fly River Delta, Gulf of Papua (Papua New Guinea). Estuar. Coast. Shelf Sci. 69, 225-245.

Hedges, J.I., Keil, R.G., 1995. Sedimentary organic matter preservation: an assessment and speculative synthesis. Mar. Chem. 49, 81-115.

Hernandez, M.T., Mills, R.A., Pancost, R.D., 2008. Algal biomarkers in surface waters around the Crozet plateau. Org. Geochem. 39, 1051-1057.

Hu, L., Guo, Z., Feng, J., Yang, Z., Fang, M., 2009a. Distributions and sources of bulk organic matter and aliphatic hydrocarbons in surface sediments of the Bohai Sea, China. Mar. Chem. 113, 197-211.

Hu, J., Peng, P.A., Chivas, A.R., 2009b. Molecular biomarker evidence of origins and transport of organic matter in sediments of the Pearl River estuary and adjacent South China Sea. Appl. Geochem. 24, 1666-1676. 
Hu, L.M., Lin, T., Shi, X.F., Yang, Z.S., Wang, H.J., Zhang, G., Guo, Z.G., 2011. The role of shelf mud depositional process and large river inputs on the fate of organochlorine pesticides in sediments of the Yellow and East China seas. Geophys. Res. Lett. 38, L03602.

Hu, L.M., Shi, X.F., Yu, Z.G., Lin, T., Wang, H.J., Ma, D.Y., Guo, Z.G., Yang, Z.S., 2012. Distribution of sedimentary organic matter in estuarine-inner shelf regions of the East China Sea: implications for hydrodynamic forces and anthropogenic impact. Mar. Chem. 142-144, 29-40.

Hu, L., Shi, X., Guo, Z., Wang, H., Yang, Z., 2013. Sources, dispersal and preservation of sedimentary organic matter in the Yellow Sea: the importance of depositional hydrodynamic forcing. Mar. Geol. 335, 52-63.

Jeng, W.L., Lin, S., Kao, S.J., 2003. Distribution of terrigenous lipids in marine sediments off northeastern Taiwan. Deep Sea Res. Part II: Topical Studies Oceanogr. 50, 1179-1201.

Leeming, R., Ball, A., Ashbolt, N., Nichols, P., 1996. Using faecal sterols from humans and animals to distinguish faecal pollution in receiving waters. Water Res. 30, 2893-2900.

Li, F.Y., Gao, S., Jia, J.J., Zhao, Y.Y., 2002. Contemporary deposition rates of fine grained sediments in the Bohai and Yellow Seas. Oceanol. Limnol. Sinica 37 (4), 364-369 (in Chinese with English abstract).

Lim, D.I., Jung, H.S., Choi, J.Y., Yang, S., Ahn, K.S., 2006. Geochemical compositions of river and shelf sediments in the Yellow Sea: grain-size normalization and sediment provenance. Cont. Shelf Res. 26, 15-24.

Lim, D.I., Choi, J.Y., Jung, H.S., Rho, K.C., Ahn, K.S., 2007. Recent sediment accumulation and origin of shelf mud deposits in the Yellow and East China Seas. Prog. Oceanogr. 73, 145-159.

Liu, D.Y., Keesing, J.K., Xing, Q.G., Shi, P., 2009. World's largest macroalgal bloom caused by expansion of seaweed aquaculture in China. Mar. Pollut. Bull. 58, 888-895.

Liu, L.Y., Wang, J.Z., Guan, Y.F., Zeng, E.Y., 2012. Use of aliphatic hydrocarbons to infer terrestrial organic matter in coastal marine sediments off China. Mar. Pollut. Bull. 64, 1940-1946.

Logan, G.A., Eglinton, G., 1994. Biogeochemistry of the Miocene lacustrine deposit, at Clarkia, northern Idaho, U.S.A. Org. Geochem. 21, 857-870.

Lü, X., Zhai, S., 2006. Distributions and sources of organic biomarkers in surface sediments from the Changjiang (Yangtze River) Estuary, China. Cont. Shelf Res. $26,1-14$.

Meyers, P.A., 1997. Organic geochemical proxies of paleoceanographic, paleolimnologic and paleoclimatic processes. Org. Geochem. 27, 213-250.

Meyers, P.A., 2003. Applications of organic geochemistry to paleolimnological reconstructions: a summary of examples from the Laurentian Great Lakes. Org. Geochem. 34, 261-289.

Meyers, P.A., Ishiwatari, R., 1993. Lacustrine organic geochemistry-an overview of indicators of organic matter sources and diagenesis in lake sediments. Org. Geochem. 20, 867-900.

Milliman, J.D., Meade, R.H., 1983. World-wide delivery of river sediment to the oceans. J. Geol. 91 (1), 1-21.

Mudge, S.M., Norris, C.E., 1997. Lipid biomarkers in the Conwy Estuary (North Wales, UK): a comparison between fatty alcohols and sterols. Mar. Chem. 57, 61-84.

Poynter, J., Eglinton, G., 1990. Molecular composition of three sediments from Hole 717C: the Bengal fan. In: Proceedings of the Ocean Drilling Program, Scientific Results, vol. 116.
Prahl, F.G., Ertel, J.R., Goni, M.A., Sparrow, M.A., Eversmeyer, B., 1994. Terrestrial organic carbon contribution to sediments on the Washington margin. Geochim. Cosmochim. Acta 58, 3035-3048.

Qiao, S., Shi, X., Zhu, A., Liu, Y., Bi, N., Fang, X., Yang, G., 2010. Distribution and transport of suspended sediments off the Yellow River (Huanghe) mouth and the nearby Bohai Sea. Estuar. Coast. Shelf Sci. 86, 337-344.

Quemeneur, M., Marty, Y., 1992. Sewage influence in a macrotidal estuary: fatty acid and sterol distributions. Estuar. Coast. Shelf Sci. 34, 347-363.

Rampen, S.W., Volkman, J.K., Hur, S.B., Abbas, B.A., Schouten, S., Jameson, I.D. Holdsworth, D.G., Bae, J.H., Sinninghe Damste, J.S., 2009. Occurrence of gorgosterol in diatoms of the genus Delphineis. Org. Geochem. 40, 144-147.

Schefuß, E., Ratmeyer, V., Stuut, J.B.W., Jansen, J.H.F., Sinninghe Damsté, J.S., 2003. Carbon isotope analyses of $n$-alkanes in dust from the lower atmosphere over the Central Eastern Atlantic. Geochim. Cosmochim. Acta 67, 1757-1767.

Schmidt, F., Hinrichs, K.U., Elvert, M., 2010. Sources, transport, and partitioning of organic matter at a highly dynamic continental margin. Mar. Chem. 118, 37-55.

Seki, O., Yoshikawa, C., Nakatsuka, T., Kawamura, K., Wakatsuchi, M., 2006. Fluxes, source and transport of organic matter in the western Sea of Okhotsk: stable carbon isotopic ratios of $n$-alkanes and total organic carbon. Deep Sea Res. Part I $53,253-270$.

Shi, W., Wang, M.H., 2009. Green macroalgae blooms in the Yellow Sea during the spring and summer of 2008. J. Geophys. Res. 114, C12010.

Volkman, J.K., 1986. A review of sterol markers for marine and terrigenous organic matter. Org. Geochem. 9, 83-99.

Volkman, J., 2003. Sterols in microorganisms. Appl. Microbiol. Biotechnol. 60, 495506.

Volkman, J.A., Barrett, S.M., Blackburn, S.I., Mansour, M.P., Sikes, E.L., Gelin, F., 1998. Microalgal biomarkers: a review of recent research developments. Org. Geochem. 29, 1163-1179.

Wang, X.C., Chen, R.F., Berry, A., 2003. Sources and preservation of organic matter in Plum Island salt marsh sediments (MA, USA): long-chain n-alkanes and stable carbon isotope compositions. Estuar. Coast. Shelf Sci. 58, 917-928.

Xing, L., Zhang, H., Yuan, Z., Sun, Y., Zhao, M., 2011. Terrestrial and marine biomarker estimates of organic matter sources and distributions in surface sediments from the East China Sea shelf. Cont. Shelf Res. 31, 1106-1115.

Xiong, Y.Q., Wu, F.C., Fang, J.D., Wang, L.F., Li, Y., Liao, H.Q., 2010. Organic geochemical record of environmental changes in Lake Dianchi, China. China J. Paleolimnol. 44, 217-231.

Xu, Y., Jaffé, R., 2007. Lipid biomarkers in suspended particles from a subtropical estuary: assessment of seasonal changes in sources and transport of organic matter. Mar. Environ. Res. 64, 666-678.

Yang, Z.S., Liu, J.P., 2007. A unique Yellow River-derived distal subaqueous delta in the Yellow Sea. Mar. Geol. 240, 169-176.

Zhang, J., Huang, W.W., Zhang, J., Wang, Q., 1992. Transport of particulate heavy metals towards the East China Seas: a preliminary study and comparison. Mar. Chem. 40, 161-178.

Zhang, L., Zhang, J., Gong, M., 2009. Size distributions of hydrocarbons in suspended particles from the Yellow River. Appl. Geochem. 24, 1168-1174.

Zhang, L.J., Wang, L., Cai, W.J., Liu, D.M., Yu, Z.G., 2013. Impact of human activities on organic carbon transport in the Yellow River. Biogeosciences 10, 2513-2524. 